\title{
The Challenges of the Engineering Inspection of Pipelines and Heat Engines by Temperature Deformation and Stress
}

\author{
Eduard A. Mikaelian"1, Saif A. Mouhammad2* \\ ${ }^{1}$ Gubkin Russian State University of Oil and Gas, Moscow, Russia \\ ${ }^{2}$ Physics Department, Faculty of Science, Taif University, Taif, Saudi Arabia \\ Email: "saifnet70@hotmail.com
}

Received 7 November 2015; accepted 9 January 2016; published 12 January 2016

Copyright (C 2016 by authors and Scientific Research Publishing Inc.

This work is licensed under the Creative Commons Attribution International License (CC BY). http://creativecommons.org/licenses/by/4.0/

(c) $\underset{\mathrm{EY}}{\mathbf{2}}$ Open Access

\begin{abstract}
Pipelines and engines are studied under the thermal stress during operation. With the calculated ratios obtained, it is possible to settle practical issues in operation in order to increase the reliability and safety of equipment. To this end, it is first necessary to investigate the thermal mode of the pipeline, the engine for the planned period by the operations control centre. At the same time, the equipment with the average temperature at a certain time of the year exceeding the design value should be identified. In addition, the equipment concerning the nature of jamming should be studied at the sections specified in such a way. In case of identifying the jammed sections based on the above calculated ratios by thermal deformation and stressing the necessary value of movement of the sections, it should be determined that the actual voltage does not exceed the permissible level.
\end{abstract}

\section{Keywords}

Thermal Stress, Deformation, Jamming in Pipes, Equipment, Thermal Stress Characteristics

\section{Introduction}

In the operation of one of the main types of machines in the oil, gas and energy sectors pipelines are known pipelines and engines associated with a reduction of reliability and safety [1] [2]. One of the reasons that create unsafe operational conditions for machines in that case is thermal stress, deformation, jams in the machines (rods, pipes and engines) [3] [4].

\footnotetext{
"Corresponding author.
} 
In connection with this, the article addresses the issue based on the thermodynamic ratios and thermal conductivity to build design ratios by determining the occurring thermal stresses that cause abnormal and unsafe conditions for pipelines, rods and heat engines. The obtained solutions are made available for use in the inspecting, diagnosing or during the technical examination of machines in question [5] [6].

\section{Settlement Ratios of Thermodynamics and Heat Transfer for the Thermal Stress of the Equipment}

Thermal stress occurs in engineering. In case of gas pipeline systems, thermal stress can occur in a pipeline particularly in the jammed sections, gas compressor units, pistons, turbines etc. [1] [3]. Since the gas temperature in the pipeline section is substantially above the temperature of the soil, an intensive heat exchange between the soil and pipe takes effect. The temperature along the pipeline drops but due to the high coefficient of heat transfer from gas to the wall, the wall temperature is practically the same as the gas temperature $\left(t_{g}\right)$. Since the pipeline is laid at a different temperature $\left(t_{l a}\right)$, thermal stresses and deformations will inevitably arise due to relative elongations in the linear part of the gas pipeline:

$$
\Delta L / L=\alpha_{w}\left(t_{g}-t_{l a}\right) .
$$

where $\Delta L$ —change of length of the pipeline $L ; \alpha_{w}$-coefficient of thermal, linear expansion of the pipeline and of the rode.

Due to pipeline jamming (soil or dead spots) the linear expansion can be completely destroyed. Compression stress takes place:

$$
\sigma=E \times \Delta L / L=\alpha_{w}\left(t_{g}-t_{l a}\right) \times E .
$$

where $E$ - the elasticity modulus of the rod material and of the pipe material.

These additional stresses are the greatest value in the initial section of the gas pipeline, at the output of the compressor station CS where gas has the highest temperature. A rational way to combat the thermal stress is to pre-cool gas before it enters the pipeline [2] [4]. Under certain conditions, such as permafrost gas pre-cooling to low temperatures may become the only means of gas transport. In the case of the use of special coolers, unlike air coolers, for example, the compression- or absorption-type chillers, it is expedient to install them before blowers prior to the compression process at the compression station input. It is possible for air coolers during the cold season, when there is a considerable difference in temperature between gas and ambient air temperature while the cooled gas temperature with the help of air coolers does not reach the dew point. In this case, it is possible to either gain in the power supplied on compressing the gas, or increase the capacity of the compressor station reaching $10 \%$ or more.

Changing the length of the rod $(\Delta L)$ is subject to the following law:

$$
\Delta L=\alpha_{w} \times L\left(T_{1}-T_{2}\right)=\alpha_{w} \times L \times \Delta T,
$$

where $L$-rod length; $\Delta T=T_{1}-T_{2}$ —emperature change.

If the elements of bodies, structures freely expand or constrict, i.e. are not fixed, the temperature changes do not cause stress. The change in length caused by temperature change $(\Delta T)$, is eliminated by the influence of stress $\sigma$ according to the equation:

$$
\Delta L=\sigma \times L / E,
$$

On the basis of the last two equations it follows:

$$
\alpha_{w} \times L\left(T_{1}-T_{2}\right)=\sigma \times L / E,
$$

from where:

$$
\sigma=-\alpha_{w} \times E\left(T_{1}-T_{2}\right) .
$$

If lengthening or shortening the rod is limited only in part, the last equation can be written as follows:

$$
\sigma=-k \times \alpha_{w} \times E\left(T_{1}-T_{2}\right),
$$

where $k$-factor depending on the nature of consolidation. 
The calculated ratios presented above can be used to conduct the technical inspection of pipeline sections concerning thermal strains and stresses and determine the nature of jamming. In case of clamped areas are identified on the basis of the above calculated ratios in terms of thermal strains and stresses, it may be possible to determine the necessary amount of transfer of the sections based on the condition that the actual voltage does not exceed the permissible one.

\section{Examples of the Calculated Temperature Stresses in Pipelines and Heat Engines}

\subsection{Example 1}

A steel rod $50 \mathrm{~cm}$ long is fitted between the two walls without any preload at $32^{\circ} \mathrm{C}$. What the tension in the rod at $35^{\circ} \mathrm{C}$ is going to be. How this tension will change, if the wall moves by $\Delta L=0.25 \mathrm{~mm}$ from one another. The thermal expansion coefficient and the modulus of elasticity of the material of the rod are respectively equal to $\alpha_{w}$ $=12.5 \times 10^{-6}{ }^{\circ} \mathrm{C}^{-1}$ and $E=2.04 \times 10^{6}$ bar.

We first define the tension in the rod without taking into account the nature of fixing:

$$
\sigma=\alpha_{w} \times E\left(T_{2}-T_{1}\right)=12.5 \times 10^{-6} \times 2.04 \times 10^{6}(35-32)=76.5 \mathrm{bar}=7.65 \mathrm{Mpa} .
$$

Given the nature of fixing the tension in the rod becomes equal to:

$$
\sigma=E \times \alpha_{w}\left(T_{1}-T_{2}\right)-\Delta L \times E / L=76.5-0.025 \times 2.04 \times 10^{6} / 50=943.5 \mathrm{bar}=94.35 \mathrm{Mpa} .
$$

The coefficient, which depends on the nature of fixing the rod, is determined by the following formula:

$$
k=1-\Delta L /\left[\alpha \times L\left(T_{2}-T_{1}\right)\right]=1-0.025 / 12.5 \times 10^{-6} \times 50 \times 3=-12.3 .
$$

In view of the obtained values of the coefficient, the tension in the rod will fall sharply.

\subsection{Example 2}

A steel pipe is clamped at a section with the length $L=1000 \mathrm{~m}$ without any preload at an average temperature $T_{1}$ $=23^{\circ} \mathrm{C}$. What voltage will be in the pipe with an increase in its temperature to $T_{2}=26^{\circ} \mathrm{C}$, which is due to its increased load. How this tension will change in the pipeline, if its clamped ends will at a distance of $0.5 \mathrm{~m}$. The thermal expansion coefficient and modulus of elasticity of the pipe material are respectively equal to $\alpha_{w}=12.5 \times$ $10^{-6}{ }^{\circ} \mathrm{C}^{-1}$ and $E=2.04 \times 10^{6}$ bar.

First we determine the voltage at a given section of the pipeline when its temperature changes taking into account his clamping:

$$
\sigma=\alpha_{w} \times E\left(T_{2}-T_{1}\right)=12.5 \times 10^{-6} \times 2.04 \times 10^{6}(26-23)=76.5 \mathrm{bar}=7.65 \mathrm{Mpa} .
$$

In view of the possibility of moving the clamped ends of the pipe by $0.5 \mathrm{~m}$ the tension at the considered section will be determined from the following equations:

$$
\alpha_{w} \times L\left(T_{2}-T_{1}\right)-\sigma \times L / E-\Delta L=0
$$

from where

$$
\sigma=E \times \alpha_{w}\left(T_{2}-T_{1}\right)-\Delta L \times E / L=76.5-0.5 \times 2.04 \times 10^{6} / 1000=-943.5 \mathrm{bar}=-94.35 \mathrm{Mpa} .
$$

The coefficient, which depends on the nature of the pipeline's clamping, will be determined by the following formula:

$$
k=1-\Delta L /\left[\alpha_{w} \times L\left(T_{2}-T_{1}\right)\right]=1-0.5 / 12.5 \times 10^{-6} \times 1000(26-23)=-12.3 .
$$

Since the clamped ends of the pipe can be moved, it is possible to reduce the tension at the considered section to a value that does not exceed the allowable stress of the pipe material. Thus, the possibility of moving the clamped ends of the pipe to the desired value makes it possible to prevent rupture and destruction of the pipeline [6] [7].

The objectives of the technical inspection of pipeline sections by the thermal deformation and stress the nature of clamping. If there are any clamped areas on the basis of the above calculated ratios of thermal deforma- 
tions and stresses, it may be necessary to determine the amount of movement of the sections based on the condition that the actual stress does not exceed the permissible one.

\subsection{Example 3}

According to the pipeline temperature data, for the coming period is set exceeding the mean pipe temperature by 5 degrees at the section with the length of $10,000 \mathrm{~km}$. To determine the value by which it is necessary to shift the considered section by its ends, so that the actual stress by the thermal deformations in the pipeline does not exceed the permissible $\sigma=720 \mathrm{Mpa}$. The thermal expansion coefficient and modulus of elasticity of the pipe material are taken to be equal, respectively $\alpha_{w}=12.5 \times 10^{-6}{ }^{\circ} \mathrm{C}^{-1}$ and $E=2.04 \times 10^{6}$ bar $=0.204 \times 10^{6} \mathrm{Mpa}$.

The above problem is an example of this kind of problems of technical inspection of pipelines by thermal deformation and stress, which are offered for use in the inspection, diagnosis, or during the technical examination of pipelines [8] [9].

\subsection{Example 4}

\section{Determination of the Actual Thermal Stresses in the Cylinder Group Induced by}

Abnormalities in the Engine

The presented problem is associated with the definition of thermal deformations that can cause scratching in the moving parts of the engine cylinder. The initial data set as follows: $D$-diameter of the cylinder; $b$-the gap between the piston and cylinder; the piston material and its characteristics: $\alpha_{w}$-the coefficient of the linear thermal expansion; $E$-modulus of elasticity.

Calculations are made for a diesel engine with the compression ratio equal to $\varepsilon=v_{1} / v_{2}=12.5$. The rest of the original data and additional conditions of the problem are given in the course of solving. The solution of the problem begins by determining the maximum temperature of the operating procedure for the engine in the following sequence. The molecular weight of the working mixture is determined by the composition of the combustion products: oxygen $-\mathrm{O}_{2}=0.08$; nitrogen $-\mathrm{N}_{2}=0.72$; carbon dioxide- $\mathrm{CO}_{2}=0.14$; water vapour $-\mathrm{H}_{2} \mathrm{O}=0.06$ :

$$
\mu=1 /(0.08 / 32+0.72 / 28+0.14 / 44+0.06 / 18)=28.98 \mathrm{~kg} / \mathrm{mol} \text {. }
$$

The characteristic constant of the gas mixture:

$$
R=8314 / \mu=8314 / 28.98=286.9 \mathrm{~J} /(\mathrm{kg} \cdot \mathrm{K}) .
$$

The first average mass isobaric and isochoric heat capacities and adiabatic indices:

$$
\begin{gathered}
c_{p m}=\sum_{i=1}^{n} m_{i} \times c_{p m_{i}}=0.72 \times 1.051+0.08 \times 0.929+0.14 \times 0.859+0.06 \times 1.881 \\
=1.064 \mathrm{~kJ} /(\mathrm{kg} \cdot \mathrm{K})=1064 \mathrm{~J} / \mathrm{kg} \cdot \mathrm{K} ; \\
c_{v m}=c_{p m}-R=1064-286.9=777 \mathrm{~J} /(\mathrm{kg} \cdot \mathrm{K}) ; \\
k=c_{p m} / c_{v m}=1064 / 777=1.37 .
\end{gathered}
$$

Then the thermodynamic parameters at each point of the operating procedure are calculated (points: 1) the beginning of the compression process; 2) the beginning of the supply of heat to the working medium-the beginning of the combustion process; 3 ) and 4) beginning and the end of the enlargement process of the working medium in the cylinder) [5] [10]. Point 1 : the initial data- $p_{1}=105 \mathrm{~Pa} ; t_{1}=30^{\circ} \mathrm{C}$; from the equation of state of this point we can obtain the specific volume:

$$
v=R \times T / P=286.9 \times 303 / 10^{5}=0.869 \mathrm{~m}^{3} / \mathrm{kg} .
$$

Point 2: the initial data- $\varepsilon=v_{1} / v_{2}=12.5$, from where $v_{2}=0.869 / 12.5=0.070 \mathrm{~m}^{3} / \mathrm{kg}$; rate of expansion $\mathrm{n}=$ 1.32; from the equation of:

$$
p_{1} / p_{2}=\left(v_{2} / v_{1}\right)^{n_{1}},
$$

we derive the pressure at the end of the compression process: 


$$
p_{2}=p_{1} \times\left(v_{1} / v_{2}\right)^{n_{1}}=10^{5} \times 12.5^{1.32}=2.767 \times 10^{6} \mathrm{~Pa}=2.767 \mathrm{Mpa} .
$$

From the equation of state for point 2 we obtain the value of the absolute temperature:

$$
T_{2}=p_{2} \times v_{2} / R=2.767 \times 10^{6} \times 0.07 / 286.9=675 \mathrm{~K}=402^{\circ} \mathrm{C} .
$$

Point 3: the initial data- $v_{3} / v_{2}=1.9$; from where $v_{3}=1.9 \times 0.07=0.133 \mathrm{~m}^{3} ; p_{2}=p_{3}=2.767 \mathrm{Mpa}$.

From the corresponding equation of state we evaluate the temperature of the working medium of the engine at the beginning of the expansion process:

$$
T_{3}=p_{3} \times v_{3} / R=2.767 \times 10^{6} \times 0.133 / 286.9=1283 \mathrm{~K}=1010^{\circ} \mathrm{C} .
$$

Point 4: at $v_{4}=v_{1}=0.869 \mathrm{~m}^{3}$ from the equation of the expansion process calculated is the temperature at the end of the process:

$$
p_{4}=p_{3} \times\left(v_{3} / v_{4}\right)^{n_{2}}=2.767 \times 10^{6} \times(0.133 / 0.869)^{1.25}=0.265 \times 10^{6} \mathrm{Mpa} .
$$

The gas temperature at the end of the expansion process is determined from the equation of state:

$$
T_{4}=p_{4} \times v_{4} / R=0.265 \times 10^{6} \times 0.869 / 286.9=801 \mathrm{~K}=528^{\circ} \mathrm{C} .
$$

Thus, based on thermodynamic calculations the maximum temperature of the working medium of the engine will be equal to the temperature at the end of expansion: $T_{3}=1283 \mathrm{~K}=1010^{\circ} \mathrm{C}$.

Further, the structural and technological parameters are included as the initial data in the calculations. Cast iron is taken as piston material, for which the thermal expansion coefficient and modulus of elasticity are respectively as follows: $\alpha=1.07 \times 10^{-6} \mathrm{C}^{-1}$ and $E=10 \mathrm{bar}$; the piston diameter $D=40 \mathrm{~cm}=0.4 \mathrm{~m}$; maximum and minimum clearances between the piston and cylinder, respectively, in the upper and lower parts of the piston are recommended equal:

$$
\begin{aligned}
& b_{1}=(1 / 175-1 / 200) \times D ; \text { take } b_{1}=2.2 \mathrm{~mm} ; \\
& b_{2}=(1 / 900-1 / 1000) \times D ; \text { take } b_{2}=0.4 \mathrm{~mm} ;
\end{aligned}
$$

In the operation, the real and maximum temperature of the engine exceeds the maximum and design cycle temperature calculated using the formula (24). The growth of the real maximum temperature may occur due to all kinds of losses occurring in the running engine, high loads, deteriorating technical condition, disturbance of the cooling mode etc. [11] [12]. In this regard, the following values of the possible, actual and maximum temperatures in the engine are set:

$$
T^{1}=1333 \mathrm{~K} ; T^{2}=1383 \mathrm{~K} ; T^{3}=1433 \mathrm{~K} .
$$

The thermal elongations are calculated in the case of extensions of the minimum clearance $b_{2}=0.4 \mathrm{~mm}=$ $0.04 \mathrm{~cm}$; piston diameter $d=D-b_{2}=400-0.4=399.6 \mathrm{~mm}$.

The phenomenon of scuffing in the cylinder occurs under the condition when the temperature elongation becomes equal to or greater than the minimum clearance between the piston and cylinder.

A change in the diameter of the piston caused by an increase in temperature of the combustion products is computed for the above-taken three maximum temperature values based on the known formula:

$$
\left\{\begin{array}{l}
\Delta d^{1}=\alpha \times d\left(T^{1}-T_{1}\right)=1.07 \times 10^{-5} \times 399.6 \times(1333-1283)=0.214 \mathrm{~mm} \\
\Delta d^{2}=\alpha \times d\left(T^{2}-T_{1}\right)=1.07 \times 10^{-5} \times 399.6 \times(1383-1283)=0.428 \mathrm{~mm} \\
\Delta d^{3}=\alpha \times d\left(T^{3}-T_{1}\right)=1.07 \times 10^{-5} \times 399.6 \times(1433-1283)=0.641 \mathrm{~mm}
\end{array}\right.
$$

Then, calculated are the real gaps formed for three adopted and maximum temperatures caused by different operating conditions:

$$
\left\{\begin{array}{l}
\Delta^{1}=\Delta_{2}-\Delta d^{1}=0.420-0.214=0.206 \mathrm{~mm} \\
\Delta^{2}=\Delta_{2}-\Delta d^{2}=0.420-0.428=-0.008 \mathrm{~mm} \\
\Delta^{3}=\Delta_{2}-\Delta d^{3}=0.420-0.641=-0.221 \mathrm{~mm}
\end{array}\right.
$$


The obtained results indicate that in the risen actual temperature in the engine cylinder with respect to the maximum design temperature of the cycle by 100 degrees, the conditions for scuffing of the cylinder face, which correspond to the second value of the adopted maximum temperature value in the engine cylinder, are created. If this difference is exceeded above 100 degrees, dangerous failures in the engine are possible. Thus, in the third case, when the difference between the actual engine temperature and maximum design temperature of the cycle is equal to 150 degrees, a serious engine breakdown associated with piston seizure in the cylinder may occur.

Let us determine the temperature stress in the considered three cases of the maximum temperature in the engine by the previously given formula:

$$
\left\{\begin{array}{l}
\sigma_{1}=\alpha \times E\left(T^{1}-T_{2}\right)=1.07 \times 10^{-5} \times 10^{6} \times 50=535 \mathrm{bar} \\
\sigma_{2}=\alpha \times E\left(T^{2}-T_{2}\right)=1.07 \times 10^{-5} \times 10^{6} \times 100=1070 \mathrm{bar} \\
\sigma_{3}=\alpha \times E\left(T^{3}-T_{2}\right)=1.07 \times 10^{-5} \times 10^{6} \times 150=1605 \mathrm{bar} .
\end{array}\right.
$$

The derived results indicate that when the temperature inside the engine cylinder is exceeded relative to the maximum design cycle temperature by 100 degrees (whether in ${ }^{\circ} \mathrm{C}$ or ${ }^{\circ} \mathrm{K}$ ), there is a tension in the engine exceeding the permissible temperature equal to 800 - 900 bar for cast iron.

Similar calculations can be made for internal combustion engines made of other materials. For example, if a piston is made of aluminium, the thermal expansion coefficient and elastic modulus of the material will be equal respectively to: $2.2 \times 10^{-5}{ }^{\circ} \mathrm{C}^{-1}$ and $7.5 \times 10^{5}$ bar; the maximum and minimum clearances between the piston and cylinder of the engine are recommended within the following limits: $b_{1}=(1 / 100-1 / 125) D$ and $b_{2}=(1 / 350-1 / 500) D$.

\section{Conclusions}

The Chapter "Settlement ratio of thermodynamics and heat transfer for the thermal stress of equipment" provides the corresponding formulas to carry out the task of the technical inspection of pipeline sections and heat engines by thermal deformation and stress and to determine the nature of clamping.

The Chapter "Examples of the Calculated Temperature Stresses in Pipelines and Heat Engines" considers two groups of tasks to control the temperature mode of pipelines and heat engines.

Example 1 concerns the thermal stresses and deformation in the rods. In case of any clamped areas based on the above calculated ratios by thermal strains and stresses determined is the required value of movement of these areas based on the condition that the actual stress does not exceed the permissible one.

Examples 2 and 3 address the issues related to the technical inspection of pipelines for thermal strains and stresses based on which practical recommendations for use during the inspection, diagnosing or technical examination of pipelines and ensuring the safe operation of pipelines are presented.

Example 4 addresses some issues devoted to control the temperature mode of the cylinder group to provide a reliable and safe operation of internal combustion engines trouble-free.

\section{References}

[1] Mikaelian, E.A. (1994) Operation of Gas Turbine Pumping Units at Compressor Stations of Gas Pipelines (Ekspluatatsiya gazoturbinnykh perekachivayushchikh agregatov kompressornykh stantsii gazoprovodov). NEDRA, Moscow, 304. http://ogbus.ru/authors/Vanchin/Vanchin_3.pdf

[2] Mikaelian, E.A. (2000) Maintenance of the Power Engineering Equipment, Gas-Turbine and Gas-Compressor Units of the Gas Collection and Transfer Systems (Tekhnecheskoe obuslogivani energotekhnologicheskovo oborudivani, gazoturbinnykh perekachivayushchikh agregatov sestemi cobra e transporta gasa). Fuel and Energy, Moscow, 304. http://www.dobi.oglib.ru/bgl/5076.html

[3] Mikaelian, E.A. (2014) Research into Gas-Turbine and Gas-Pumping Units of Gas Pipelines under the Low-Pressure Gas-Transfer Technology (Esledovanye effectivnosti rabote gazoturbinnykh gazoperekachivaushikh agregatov gazoprovodov v uslovyakh nizkonapornoi tekhnalogy transporta gaza). Gas Turbo Technology, 7, 28-33. http://www.gtt.ru/content/view/1387/123/

[4] Mikaelian, E.A. (2015) Evaluation of the Effective Performance and Technical Condition of the Gas-Turbine and GasCompressor Units in Operation (Otsenka effectivnoi rabote e tekhnicheskovo sostoyani gazoturbinnykh GPA v oslovyakh Ekspluatatsiy). Gas Turbo Technology, Designated Research and Information Journal, 2, 18-22. 
http://oil-book.narod.ru/door/door2/521.htm

[5] Mikaelian, E.A. (2015) Evaluation of Mechanical Losses of Power of the Gas-Transfer Units (Otsenka mekhanecheskikh poter moshnosty gazoperekachivaushikh agregatov). Gas Turbo Technology, Designated Research and Information Journal, 3, 28-32. http://www.gtt.ru/content/view/1441/1/

[6] Mikaelian E.A. (2015) Proposals for the Harmonisation of the Characteristics of Gas-Turbine Units and Gas Centrifugal Compressors Given the Power Lost for the Mechanical Losses during Power Transmission from the Drive (Soglasovani kharakteristik gazotorbennekh ostanofak e gazovekh tsentrobegnekh kompresorof s ochotom moshnosti, teryaemoi na mekhanicheskie poteri pri peredache energy ot prevoda). Quality Management in Oil and Gas Industry, 1, 15-18. http://instoilgas.ru/d/988947/d/microsoftword-annotatsii1-15sokrrus.pdf

[7] Mikaelian, E.A. (2001) Improving the Quality, Ensuring Reliability and Safety of the Gas and Oil Mains to Improve the Serviceability (Poveshene kachestva, obesbecheny nadognosty e bezopasnosty magestralnekh gazonefteprovodof dla covershenstvovaneya ekspluatatsionnoi prigodnosty). Fuel and Energy, Moscow, 640.

[8] Mikaelian, E.A. and Mouhammad, S.A. (2015) Survey of the Gas-Turbine Gas-Compressor Units of Compressor Plants Based on the Modified Thermodynamics Model. International Journal of Alternative Fuels, 17, 1125-1131. http://recentscience.org/article/myarticles.php

[9] Vladimirov, A.I. and Kershenbaum, Y.V. (2008) Industrial Safety Compressor Stations. Management of Safety and Reliability. Inter-Sector Foundation "National Institute of Oil and Gas”, Moscow, 640. http://www.mdk-arbat.ru/bookcard?book id=3304125

[10] Mikaelian, E.A. (2015) Methods for Determining the Characteristics and Condition of Pipelines (Sposobe opredelenie kharakteristik e tekhnicheskovo coctoyanie gazoprovodof). Energetik, 5, 19-22. http://elibrary.ru/item.asp?id=23618568

[11] Mikaelian, E.A. (2014) From the Energy-Saving Technology to the Resource-Saving One, from Energy Audit to Resource Audit (Ot energosberegaushy tekhnalogy k resorsosberegaushy, ot energoaodeta k resorsoaodetu). Gas Industry, 4, 70-73. http://chemtech.ru/ktp/kompressornaya-tekhnika-i-pnevmatika-22015

[12] Mikaelian, E.A. (2014) Survey of Equipment of the Gas and Oil Transport Systems (Obsledovanie oborodivaniya gazoneftetransportnikh sestem). Heavy Engineering Industry, 4, 18-25. http://www.tiajmash.ru/ 